\title{
Clinical implication of FDG-PET/ CT in monitoring disease activity in large-vessel giant cell arteritis linked with secondary polymyalgia rheumatica
}

\author{
Yoshinori Taniguchi, Shuichi Nakayama, Yoshio Terada \\ Department of Endocrinology, Metabolism and Nephrology, Kochi University School of Medicine, Nankoku, Japan
}

Correspondence: Yoshinori Taniguchi, M.D. Address: Department of Endocrinology, Metabolism and Nephrology, Kochi Medical School, Kochi University, Kohasu, Oko-Cho, Nankoku, Kochi 783-8505, Japan. Email: taniguchiy@kochi-u.ac.jp

Received: December 30, 2013

DOI : $10.5430 /$ crim.v1n1p6
Accepted: January 13, 2014

URL: http://dx.doi.org/10.5430/crim.v1n1p6

\section{Abstract}

Seventy year-old female presented low-grade fever, neck and pelvic girdle pain, jaw claudication and pulseless without visual disturbance. Laboratory examinations showed that C-reactive protein and erythrocyte sedimentation rate (ESR) were $11 \mathrm{mg} / \mathrm{dl}$ and $123 \mathrm{~mm} / 1 \mathrm{hr}$, respectively. FDG-PET/CT findings demonstrated bilateral subclavian, carotid and femoral arteritis and aortitis in addition to bursitis and enthesitis of spinous process and pelvic girdle. We diagnosed as large-vessel giant cell arteritis (GCA) linked with secondary polymyalgia rheumatica (PMR). Glucocorticoid therapy was started, and not only these symptoms and but also abnormal findings of FDG-PET/CT were improved.

\section{Key words}

Giant cell arteritis, Polymyalgia rheumatica, Bursitis, Enthesitis, Spondyloarthritis, FDG-PET/CT

\section{I ntroduction}

Giant cell arteritis (GCA) is an inflammatory vasculopathy usually affecting large- and medium-sized arteries. Polymyalgia rheumatica (PMR) is an inflammatory disorder of unknown etiology characterized by pain and stiffness in the neck, shoulder, and pelvic girdles. GCA is closely related to PMR and the presence of biopsy-proven GCA has been demonstrated in 16\%-21\% of patients with PMR. Therefore, symptoms of PMR might also be viewed as clinical features of GCA ${ }^{[1,2]}$. We demonstrated herein a patient with large-vessel GCA linked with PMR, whose arteritis and bursitis, including asymptomatic lesions, could be detected using Positron Emission Tomography/Computed Tomography with 18F-fluorodeoxyglucose (FDG-PET/CT) scans.

\section{Case presentation}

70 year-old woman presented low-grade fever for 8 weeks, morning stiffness, neck, bilateral shoulder and pelvic girdle pain, jaw and arm claudications without visual disturbance or headache. Her physical examinations demonstrated pulseless at upper extremities but no scalp tenderness. Laboratory examinations showed the elevated inflammatory markers that C-reactive protein (CRP), erythrocyte sedimentation rate (ESR) and serum amyloid-A were $11 \mathrm{mg} / \mathrm{dl}$, 
$123 \mathrm{~mm} / 1 \mathrm{hr}$ and $2317.1 \mu \mathrm{g} / \mathrm{ml}$, respectively. Moreover, leukocytosis (white blood cell $8800 / \mu$ ), thrombocytosis (platelet $\left.37.8 \times 10^{4} / \mu \mathrm{l}\right)$ and elevated complement $(\mathrm{CH} 50>60.0 \mathrm{U} / \mathrm{ml})$ were revealed. On the other hand, serum levels of liver and muscle enzymes were all normal. FDG-PET/CT findings demonstrated high FDG uptake in bilateral subclavian, carotid and femoral arteries (see Figure 1A and C: coronal images; arrows) and FDG accumulation localized in vascular wall of ascending aorta and aortic arch (see Figure 1B: sagittal image; arrows) indicating GCA but not active atherosclerosis due to the difference of the visual grading or standardized uptake value (SUV) of vascular FDG uptake. Furthermore, high FDG uptakes in the shoulder, spinous process, ischial tuberosity and pelvic girdle were also revealed, indicating bursitis and enthesitis (see Figure 1, arrow heads). Moreover, ultrasonography showed that bursitis affected the shoulder indicating subacrominal bursitis (see Figure 1J, arrow heads). Angiography showed the stenosis of right internal carotid, left subclavian and left coronary arteries without arteriosclerosis and calcification (image not shown), indicating the findings of arteritis. The biopsy from artery was not performed because of the typical arterial involvements by FDG-PET/CT. We diagnosed as large-vessel GCA associated with secondary PMR. As previous reports ${ }^{[3-7]}$, large-vessel arteritis and bursitis/enthesitis in the present case were considered as the findings of GCA and PMR, respectively. Glucocorticoid therapy (prednisolone $40 \mathrm{mg}$ daily) was initiated and induced rapid symptomatic relief after 48 hours, suggesting that it could be considered as diagnostic criterion. Not only these symptoms and laboratory abnormalities and but also abnormal findings of FDG-PET/CT were improved (see Figure 2). Now, prednisolone $10 \mathrm{mg}$ daily could be currently maintaining a complete remission for GCA associated with PMR without flare-up.

Figure 1. Evaluation of GCA and PMR findings by FDG-PET/CT and ultrasonography before treatment. FDG-PET/CT findings demonstrated bilateral subclavian, carotid and femoral arteritis and aortitis (A-G; arrows) in addition to bursitis and enthesitis of shoulder, spinous process, ischial tuberosity and pelvic girdle (A, B, G-I; arrow heads). Ultrasonography showed that bursitis affected the shoulder indicating subacrominal bursitis ( $\mathrm{J}$; arrow heads).
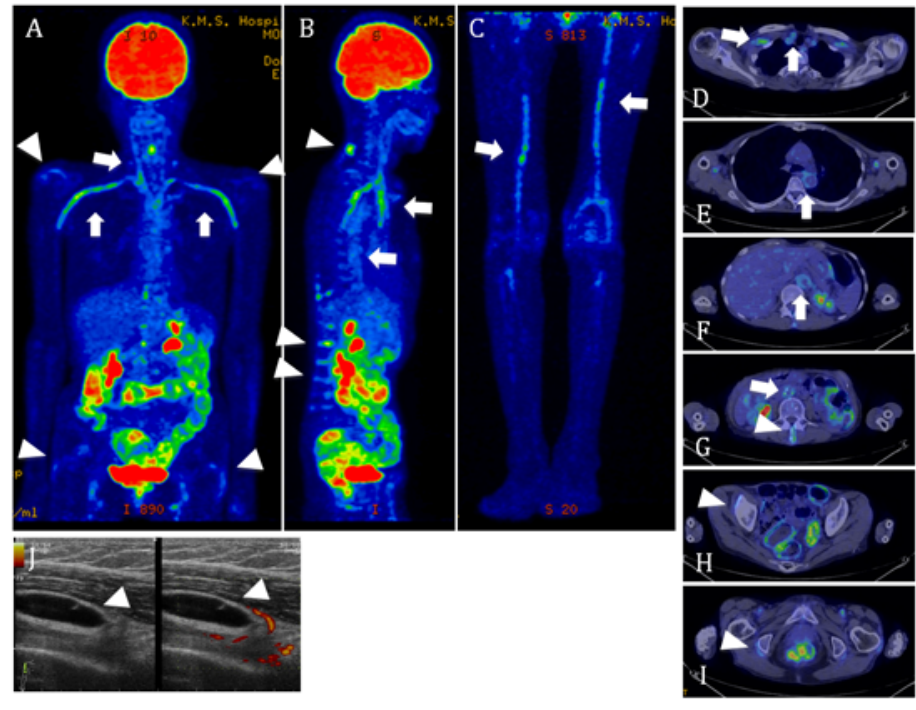

Figure 2. Evaluation of GCA and PMR findings by FDG-PET/CT after treatment. Abnormal findings of FDG-PET/CT were improved and diminished.
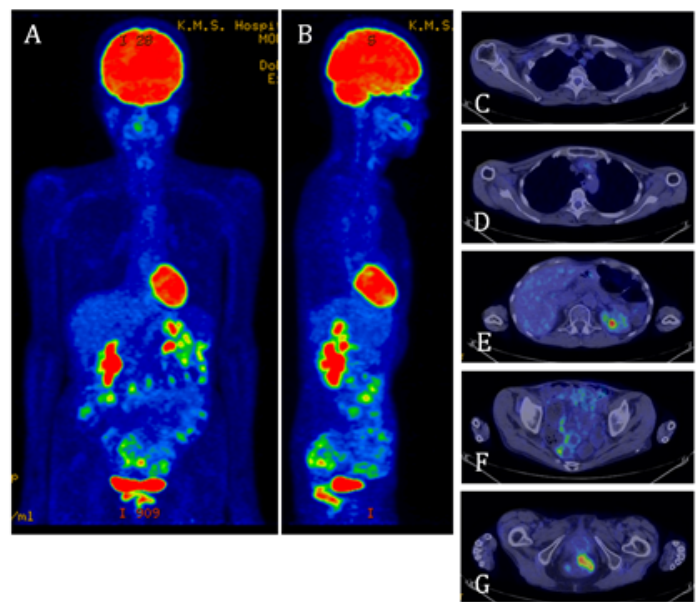


\section{Discussion}

The association of GCA and PMR generally increases after age of 50 and peaks between 70 and 80 years of age, as in the present case ${ }^{[1,2]}$. GCA and PMR occur together more frequently than expected by chance, and the main symptoms of PMR are pain and long-term stiffness in the shoulders ${ }^{[1,2]}$.

New diagnostic imaging methods for GCA and PMR have been sought. Recent several reports showed that FDG-PET/CT scans accurately, and safely identifies the multiple vessel involvements of GCA ${ }^{[3,4]}$ and bursitis lesions of PMR ${ }^{[5-7]}$. A smooth linear or long segmental pattern of FDG uptake in the aorta and its main branches is thought to be a characteristic pattern of $\mathrm{GCA}^{[8]}$, and FDG-PET/CT finding in the present case matched to this finding. Furthermore, we classified PMR in the present case, based on new classification criteria for PMR ${ }^{[9]}$. However, FDG-PET/CT between both PMR and spondyloarthritis $(\mathrm{SpA})$ could often demonstrate similar findings in lumbar spinous process, ischial tuberosity and pelvic girdle lesions ${ }^{[10-12]}$. The different points between PMR and SpA might be sacroiliitis and the response to steroid treatment. Therefore, when the elderly patient was noted to have pelvic girdle and low back pain, we should always recognize the differentiation between PMR and late-onset SpA.

In summary, FDG-PET/CT imaging helps us to evaluate widespread lesions, including asymptomatic lesions, and monitor disease activity in GCA linked, or not, with PMR, on considering the differentiation of SpA and other conditions.

\section{Acknowledgement}

We have no funding supports in this study.

\section{Disclosure statement}

The authors have declared no conflicts of interest.

\section{References}

[1] Kermani TA, Warrington KJ. Polymyalgia rheumatica. Lancet. 2013; 381: 63-72. http://dx.doi.org/10.1016/S0140-6736(12)60680-1

[2] Salvarani C, Pipitone N, Versari A, Hunder GG. Clinical features of polymyalgia rheumatica and giant cell arteritis. Nat Rev Rheumatol. 2012; 8: 509-521. http://dx.doi.org/10.1038/nrrheum.2012.97

[3] Fletcher TM, Espinola D. Positron emission tomography in the diagnosis of giant cell arteritis. Clin Nucl Med. 2004; 29: 617-619. http://dx.doi.org/10.1097/00003072-200410000-00003

[4] De Winter F, Petrovic M, Van de Wiele C, Vogelaers D, Afschrift M, Dierckx RA. Imaging of giant cell arteritis: evidence of splenic involvement using FDG positron emission tomography. Clin Nucl Med. 2000; 25: 633-634. http://dx.doi.org/10.1097/00003072-200008000-00018

[5] Adams H, Raijmakers P, Smulders Y. Polymyalgia rheumatica and interspinous FDG uptake on PET/CT. Clin Nucl Med. 2012; 37: 502-505. http://dx.doi.org/10.1097/RLU.0b013e3182485098

[6] Toriihara A, Seto Y, Yoshida K, Umehara I, Nakagawa T, Liu R, et al. F-18 FDG PET/CT of polymyalgia rheumatica. Clin Nucl Med. 2009; 34: 305-306. http://dx.doi.org/10.1097/RLU.0b013e31819e51fd

[7] Dos Anjos DA, Dos Anjos RF, de Paula WD, Sobrinho AB. F-18 FDG PET/CT in giant cell arteritis with polymyalgia rheumatica. Clin Nucl Med. 2008; 33: 402-404. http://dx.doi.org/10.1097/RLU.0b013e318170d46a

[8] Besson FL, Parienti JJ, Bienvenu B, Prior JO, Costo S, Bouvard G, et al. Diagnostic performance of 18F fluorodeoxyglucose positron emission tomography in giant cell arteritis: a systemic review and meta-analysis. Eur J Nucl Med Mol Imaging. 2011; 38: 1764-1772. http://dx.doi.org/10.1007/s00259-011-1830-0

[9] Dasgupta B, Cimmino MA, Kremers HM, Schmidt WA, Schirmer M, Salvarani C, et al. 2012 Provisional classification criteria for polymyalgia rheumatica: a European League Against Rheumatism/American College of Rheumatology collaborative initiative. Arthritis Rheum. 2012; 64: 943-954. http://dx.doi.org/10.1002/art.34356 
[10] Taniguchi Y, Arii K, Kumon Y, Fukumoto M, Ohnishi T, Horino T, et al. Positron emission tomography/computed tomography: a clinical tool for evaluation of enthesitis in patients with spondyloarthritides. Rheumatology. 2010; 49: 348-354. http://dx.doi.org/10.1093/rheumatology/kep379

[11] Yamashita H, Kubota K, Takahashi Y, Minamimoto R, Morooka M, Kaneko H, et al. Similarities and differences in fluorodeoxyglucose positron emission tomography/computed tomography findings in spondyloarthropathy, polymyalgia rheumatica and rheumatoid arthritis. Joint Bone Spine. 2013; 80: 171-177.

[12] Salvarani C, Barozzi L, Boiardi L, Pipitone N, Bajocchi GL, Macchioni PL, et al. Lumbar interspinous bursitis in active polymyalgia rheumatica. Clin Exp Rheumatol. 2013; 31: 526-531. http://dx.doi.org/10.1016/j.jbspin.2012.04.006 